\title{
Integration of Knowledge and Practice of Nurses' Primary Health Care Roles in Hospital
}

\author{
Tamang (Thanju) $\mathrm{S}^{1}$ \\ ${ }^{1}$ National Institute of Public Health, Saitama, Japan
}

\section{ABSTRACT}

\begin{abstract}
Background: PHC concept was incorporated in nursing curricula (1987) to equip nurses with necessary knowledge and skills to perform their PHC roles. The aim was to investigate the integration of knowledge and practice of nurses' PHC roles as perceived by the nurse and patient and the relationship with its influencing variables.

Methods: A descriptive study involved nurses and patients from government and non-government hospitals using a structured questionnaire. Nonparametric statistics, known for their appropriateness for small samples, were used to examine the research questions.

Results: Integration of knowledge and practice of nurses' PHC role was positively reflected in hospitals even though most roles practices were in moderate extent and the significant difference in nurses' role practices were experienced by the patients $(\mathrm{P}<0.001)$. The nurses' $\mathrm{PHC}$ role practice was influenced by supervision $(\mathrm{P}<0.001)$ of work and role of motivator, but were not influenced by other variables.

Conclusion: Based on the study findings, an increased in knowledge resulted in an increased in PHC role practice. Therefore, good nursing education program is very important for the nurses to practice PHC roles efficiently and effectively in hospital. There is need for nurses to understand and deliver nursing care congruent with patient's perception of quality nursing care. With the regular and facilitative supervision, the nurses will have guidance, encouragement, and resources to perform well.

Key words: PHC, Clinician, Developmental, Facilitative, Supportive.
\end{abstract}

\section{INTRODUCTION}

Nepal's health care delivery system is based on PHC concept that is responsive to people's health need and provided in an equitable, dignified, personalized, and caring manner."1-3

The PHC based nursing curriculum was developed (1987) with the intention to produce nurses with the knowledge and skills to provide comprehensive health care. Discrepancy between nursing theory and practice has long been a source of concern to teachers, practitioners and learners. ${ }^{4,5}$
Orem's Self-Care Model is used as conceptual framework that explains the self-care needs and abilities of the patient with three classifications of nursing systems (Figure 1). These nursing systems are viewed as the nurse's roles that consist of Clinician, Facilitative, Development, and Supportive roles.

Previous study showed that nurse's care through different activities is extensive in hospital. ${ }^{6,7}$

The purpose of this study is to investigate the integration of knowledge and practice of nurses' different PHC roles in non-government and government hospitals as

Correspondence: Mrs. Shakuntala Tamang (Thanju), Principal,Tansen Nursing School, Tansen-10, Palpa, Nepal. Phone: +977-75-520156, Email: sthanju@ntc. net.np 
perceived by the nurse and patient and its relationship to the types of institution, length of professional practice, educational attainment, supervision of work, in-service education, and nurses' actual role to perform $\mathrm{PHC}$ roles.

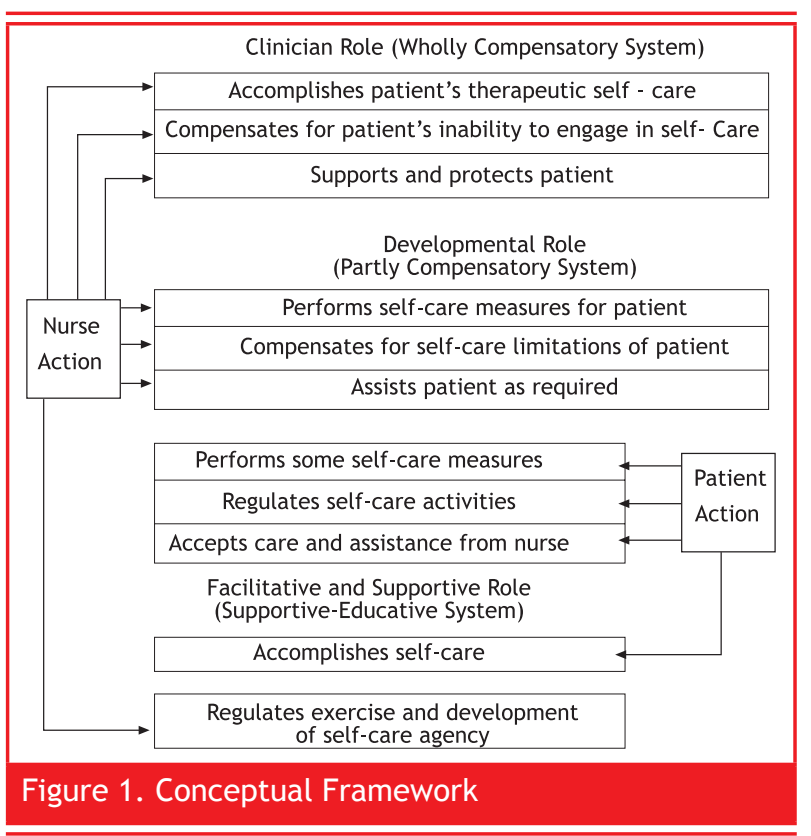

\section{METHODS}

This study employed a descriptive method of investigation. The nurses and patients were participants from one government and two non-government hospitals. The study was conducted from October 2006 to August 2007.

Data were gathered from 200 nurses and 200 patients. In the nurse's questionnaire, both independent and dependent variables were designated. The questionnaire for knowledge and practice were put in one sheet to compare its integration and it was subjected to a critique for validity to the nurses who were administrators and educators in different institutions.

Only the nurses working in the day and evening shifts were considered in this study (sentences omitted). The patients included in this study were those confined for at least three days in hospital. This study did not consider the patients who had psychiatric problems.

This structured questionnaires for nurses included basic characteristic, the extent of knowledge and practice and the influencing factors to perform PHC roles.

The extent of the performance is shown in 4 different roles; each contains 10 different activities under (1) Clinician Role (CR), (2) Developmental Role (DR), (3) Facilitative Role (FR), and (4) Supportive Role (SR). A
Likert-scale was developed to grade the extent of nurses' $\mathrm{PHC}$ role practice (1 to 4 ).

The statistical test was conducted by non-parametric methods (the Mann-Whitney $U$ test, Kruskal-Wallis test, and Spearmen's correlation coefficient). Hypotheses were tested at 0.05 level of significance. Data were analyzed using the statistical Package of Social Sciences (SPSS) version 11.5.8 for windows.

\section{RESULTS}

More than $60 \%$ of the nurses were having work experience of below five years and $82 \%$ nurses had academic qualification of proficiency certificate level in nursing. Among the nurses, the nurses working in the governmental hospital had longer carrier and higher educational attainment than those of the non-governmental hospital (Table 1). There was a significance difference in the extent of nurses' roles regarding types of institutions and supervision of work but no differences found in organized in-service training among two institutions.

The extent of nurses PHC roles were higher in nongovernment hospital compared with the extent of PHC roles in government hospital. Among the roles, in both types of institutions, SR role had lower extent in both knowledge and practice (Table 2).

Nurses experienced their PHC roles were influenced by their role of motivator $(p<0.001)$ in actual role practice but no statistically significant difference were found in nurses' PHC roles and the other actual role practices (Table 3).

In addition to the type of institution $(p<0.001)$, the supervision of work showed the significant difference $(p<0.024)$ of nurses PHC roles. There was no significant difference according to the length of professional practice, and educational attainment (Table 4).

The patient experienced significant difference $(p<0.001)$ regarding nurses' $\mathrm{PHC}$ roles in both types of institutions, similarly the patients and nurses had different perceptions regarding nurses' PHC roles (Tables 5 and 6 ).

There was a positive correlation (Spearman's correlation coefficient $=0.600, p<0.001$ ) of knowledge and practice of nurses' PHC roles in hospital. This would suggest that if there is increase in knowledge there is increase in practice too (Figure 2).

\section{DISCUSSION}

This study was undertaken to assess the integration of knowledge and practice of nurses in relation to their PHC roles in government and non- government hospitals as perceived by the nurses and their patients. The 


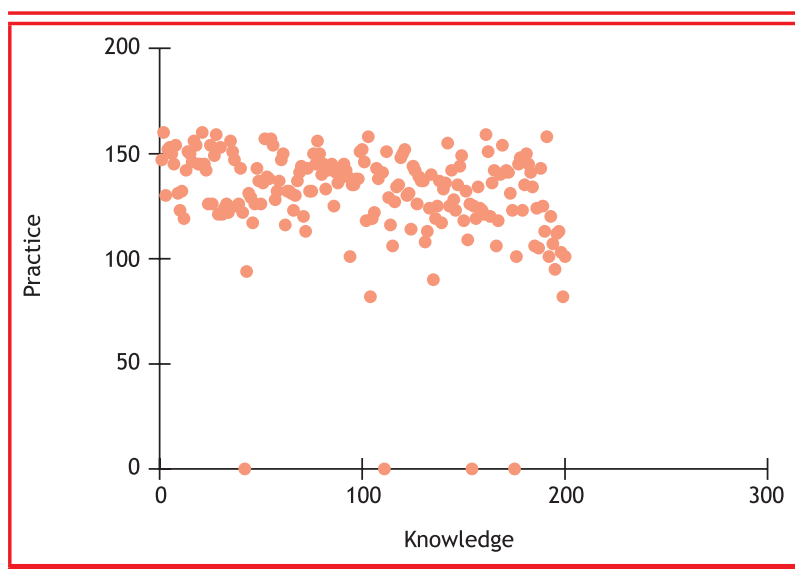

Figure 2. Integration of Knowledge and Practice

variations between the perceptions of the nurse and her patients in the extent of the implementation of nurses PHC roles and the influencing variables in nurses' PHC roles in the hospitals were examined.

Though the total PHC of nurse practice was in moderate extent, according to the findings, the nurses have perceived their practice of PHC role as clinician being extensively performed in both types of hospitals. These roles were considered nurses' fundamental roles in the PHC system which is supported by the Canadian Nursing Association 9.

Nurses had extensive knowledge of their PHC roles in both types of hospitals, however, the extents of the practice were found to be different. The nurses' four $\mathrm{PHC}$ roles were extensively practiced in non-government hospital, whereas, in government hospital, the practice of clinician role was extensive but other PHC roles, i.e., developmental, facilitative and supportive roles, were in moderate extent as perceived by the nurse themselves. This result could be due to the working culture of the hospital ward. It was observed that the nurses were busy with following doctor's orders and meeting the physical needs of the patients. It was also suggested that non-government hospitals seemed to incorporate PHC roles in their actual roles in the hospitals, and the basic reason would be that they were influenced by the motivation provided by their supervisors. In non-government hospitals the process of decision making was shorter than in the government hospital, which would suggest that the taking nursing action were more simplified and quicker. Besides, the significant difference would have been also suggested due to the system of governance of the hospitals. Nongovernment hospitals were private and mission hospitals where patient pays huge amount of money for the health services and they expect improved quality nursing care from the nurses. These interpretations are supported by Gilson, et al.: the private institutions promote diversity and competition in health care provision whereas, in contrary, in government hospital, this is less likely to happen. Nurses' knowledge and practice of PHC roles were influenced by the type of institutions, which would suggest that the system of governance of institutions, the policy and the rules would influence the nurses' PHC roles. This is supported by Gilson, et al., according to them; the government supported institution is hampered by delays in disbursement, lack of flexibility, and economic constraints 10 .

Among the role practice, supportive role had the lowest score in both types of hospitals. This supportive role of a nurse provides a support system and the provision of a safe, appropriate health service. In this role, the nurse is concerned with supervision, teaching, and a managerial role where she performs different stages of management process. The nurses were found to be reluctant to practice this kind of job, where it requires critical thinking, application of research based knowledge and decision making skills.

Nurses' PHC roles practice were influenced by the supervision of the work. This would suggest that the nurses were motivated through continuing education provided by the supervisors. In both types of hospitals, nurses acknowledged the importance of supervision in their works regarding the knowledge of PHC roles. That is what Tavrow, et al. also suggested: they say that with regular and facilitative supervision, it is expected that the health care providers will have the guidance, encouragement and resources they need to perform well 11.

The performances of the nurses' different PHC roles were not determined by the length of professional practice, educational attainment, and in-service education and actual role practices. However, nurses experienced that their PHC roles were influenced by the role of motivator in actual role in the hospital.

There was a positive relationship between the knowledge and practice of the nurses' $\mathrm{PHC}$ roles in the hospital, which means an increase in knowledge showed an increase in practice of the nurses. It was noted that the practice of PHC roles was depended upon the knowledge the nurses had in their theory class. This is also supported by Mann and Byrnes 12.

The patient experienced differently regarding the practice of nurses' PHC roles in both types of hospitals. The patient perceived the nurses' practices of all four PHC roles being in moderate extent. Among four PHC roles; the FR role, as perceived by the patient, was rated the lowest. The finding suggests that the nurses were lacking in their facilitative role. The facilitative role would have included the nurses working in partnership 
with people- individuals, families, and community population to achieve the shared goal of health for all and that is why it is nursing 13 . When the PHC concept is used in nursing; especially in hospital, it is nurse's role as a facilitator to make the health services available, feasible, acceptable, and accessible to the patient. The nurse as facilitator of health services provides the framework within which the patient in the hospital can work. It is the means by which the hospital policy can be translated to the patients and which can allocate resources by which and health cares developed.
Perla suggests that, patient satisfaction incorporates the needs of the patient and the goals of their health care provider 15. Patient's perceptions are important factors to determine the quality of health services. This is also very important to bridge the gap between theory and practices.

There is a pressing need to understand client's perceptions of their experiences in receiving care to match the roles and responsibilities of nurses which helps to stay health care close to the consumer.

Table 1. Basic and general characteristics of nurse participants

\begin{tabular}{|c|c|c|c|c|c|}
\hline \multirow{2}{*}{ Variables } & \multicolumn{2}{|c|}{ Government $(\mathrm{N}=100)$} & \multicolumn{2}{|c|}{ Non-Government $(\mathrm{N}=100)$} & \multirow{2}{*}{ P-value } \\
\hline & $\mathrm{n}$ & (\%) & $\mathrm{n}$ & (\%) & \\
\hline \multicolumn{6}{|l|}{ Length of Professional Practice } \\
\hline 5 years or below & 50 & $(50.0 \%)$ & 70 & $(70.0 \%)$ & 0.005 \\
\hline 6 to 10 years & 15 & $(15.0 \%)$ & 12 & $(12.0 \%)$ & \\
\hline 11 to 15 years & 8 & $(8.0 \%)$ & 9 & $(9.0 \%)$ & \\
\hline Over 16 years & 27 & $(27.0 \%)$ & 9 & $(9.0 \%)$ & \\
\hline \multicolumn{6}{|l|}{ Educational Attainment } \\
\hline Proficiency certificate level & 74 & $(74.0 \%)$ & 90 & $(90.0 \%)$ & 0.003 \\
\hline Bachelor or more in nursing & 26 & $(26.0 \%)$ & 10 & $(10.0 \%)$ & \\
\hline \multicolumn{6}{|l|}{ To get supervision in the work } \\
\hline Yes & 92 & $(92.0 \%)$ & 95 & $(95.0 \%)$ & 0.002 \\
\hline No & 8 & $(8.0 \%)$ & 5 & $(5.0 \%)$ & \\
\hline \multicolumn{6}{|c|}{ Organized in-service education in the hospital } \\
\hline Yes & 40 & $(40.0 \%)$ & 42 & $(42.0 \%)$ & 0.774 \\
\hline No & 60 & $(60.0 \%)$ & 58 & $(58.0 \%)$ & \\
\hline
\end{tabular}

Table 2. Extent of the nurses' PHC roles of practice and knowledge as perceived by nurses in non-government and government hospitals

\begin{tabular}{|c|c|c|c|}
\hline Extent of PHC Roles & $\begin{array}{c}\text { Government }(n=100) \\
\text { Mean }(S D)\end{array}$ & $\begin{array}{c}\text { Non-Government }(n=100) \\
\text { Mean (SD) }\end{array}$ & P-value \\
\hline \multicolumn{4}{|l|}{ Knowledge } \\
\hline Clinician Role & $38.8(2.3)$ & $37.3(3.5)$ & $<0.001$ \\
\hline Developmental Role & $38.1(3.3)$ & $36.1(4.3)$ & $<0.001$ \\
\hline Facilitative Role & $37.9(3.2)$ & $36.3(4.6)$ & $<0.003$ \\
\hline Supportive Role & $37.4(3.6)$ & $35.9(4.1)$ & $<0.003$ \\
\hline Total & $152.2(10.8)$ & $145.6(14.7)$ & $<0.001$ \\
\hline \multicolumn{4}{|l|}{ Practice } \\
\hline Clinician Role & $35.5(3.1)$ & $33.3(4.4)$ & $<0.001$ \\
\hline Developmental Role & $34.8(3.7)$ & $31.9(5.2)$ & $<0.001$ \\
\hline Facilitative Role & $35.0(3.8)$ & $32.0(5.1)$ & $<0.001$ \\
\hline Supportive Role & $32.8(4.5)$ & $30.9(4.7)$ & $<0.004$ \\
\hline Total & $138.1(13.2)$ & $128.1(17.4)$ & $<0.001$ \\
\hline
\end{tabular}


Integration of Knowledge and Practice of Nurses' Primary Health Care Roles in Hospital

\begin{tabular}{|c|c|c|c|c|}
\hline Actual Role & $\begin{array}{l}\text { Role Practice } \\
\text { Mean (SD) }\end{array}$ & P-value & $\begin{array}{l}\text { Role Knowledge } \\
\text { Mean (SD) }\end{array}$ & P-value \\
\hline \multicolumn{5}{|l|}{ Leader } \\
\hline Yes $(n=155)$ & $134.5(15.0)$ & 0.105 & $149.0(12.4)$ & 0.334 \\
\hline No $(n=45)$ & $128.8(19.2)$ & & $146.7(16.0)$ & \\
\hline \multicolumn{5}{|l|}{ Coordinator } \\
\hline Yes $(n=138)$ & $133.6(15.6)$ & 0.790 & $149.3(12.99)$ & 0.702 \\
\hline No $(n=62)$ & $132.3(17.4)$ & & $148.5(14.1)$ & \\
\hline \multicolumn{5}{|l|}{ Motivator } \\
\hline Yes $(n=114)$ & $136.7(14.8)$ & 0.001 & $150.7(12.3)$ & $<0.021$ \\
\hline No $(n=86)$ & $128.7(16.9)$ & & $147.0(14.3)$ & \\
\hline \multicolumn{5}{|l|}{ Facilitator } \\
\hline Yes $(n=132)$ & $134.5(15.3)$ & 0.217 & $150.3(12.4)$ & 0.063 \\
\hline No $(n=68)$ & $131.3(17.6)$ & & $146.8(14.7)$ & \\
\hline \multicolumn{5}{|c|}{ Direct care provider } \\
\hline Yes $(n=150)$ & $133.6(16.0)$ & 0.560 & $149.2(13.3)$ & 0.511 \\
\hline No $(n=50)$ & $132.0(17.0)$ & & $148.6(13.5)$ & \\
\hline \multicolumn{5}{|l|}{ Manager } \\
\hline Yes $(n=114)$ & $133.8(16.1)$ & 0.582 & $148.0(14.3)$ & 0.289 \\
\hline No $(n=86)$ & $132.5(16.3)$ & & $150.5(11.7)$ & \\
\hline \multicolumn{5}{|l|}{ Researcher } \\
\hline Yes $(n=94)$ & $134.4(16.6)$ & 0.337 & $148.3(14.6)$ & 0.480 \\
\hline No $(n=106)$ & $132.5(16.0)$ & & $149.8(12.1)$ & \\
\hline \multicolumn{5}{|l|}{ Educator } \\
\hline Yes $(n=146)$ & $133.2(15.8)$ & 0.975 & 147.9. (114.9) & 0.369 \\
\hline No $(n=54)$ & $133.0(13.82)$ & & $149.4(12.9)$ & \\
\hline
\end{tabular}

Table 4. Comparison of nurses' PHC role practice and knowledge according to the variables

\begin{tabular}{|c|c|c|c|c|}
\hline & $\begin{array}{l}\text { Role Practice } \\
\text { Mean (SD) }\end{array}$ & P-Value & $\begin{array}{l}\text { Role. Knowledge } \\
\text { Mean (SD) }\end{array}$ & P-Value \\
\hline \multicolumn{5}{|l|}{ Institution } \\
\hline Government $(n=100)$ & $128.2(17.4)$ & $<0.001$ & $145.7(14.7)$ & $<0.001$ \\
\hline Non-Government $(n=100)$ & $138.2(13.1)$ & & $152.4(10.8)$ & \\
\hline \multicolumn{5}{|l|}{ Length of professional practice } \\
\hline 5 years or below $(n=120)$ & $133.5(16.1)$ & 0.950 & $149.7(13.5)$ & 0.627 \\
\hline 6 to 10 years $(n=27)$ & $132.3(16.4)$ & & $149.1(12.7)$ & \\
\hline 11 to 15 years $(n=17)$ & $133.2(13.5)$ & & $147.0(13.3)$ & \\
\hline Over 16 years $(n=36)$ & $133.2(16.1)$ & & $147.6(13.9)$ & \\
\hline \multicolumn{5}{|l|}{ Educational attainment } \\
\hline Proficiency certificate level $(n=164)$ & $133.2(16.8)$ & 0.918 & $149.6(13.2)$ & 0.097 \\
\hline Bachelor or more in nursing $(n=36)$ & $133.3(17.9)$ & & $146.5(13.6)$ & \\
\hline \multicolumn{5}{|l|}{ Supervision in the work } \\
\hline Yes $(n=187)$ & $134.2(15.37)$ & $<0.007$ & $149.9(12.2)$ & 0. $<024$ \\
\hline No $(n=13)$ & $119.0(21.2)$ & & $136.3(20.6)$ & \\
\hline \multicolumn{5}{|l|}{ Organized in-service education } \\
\hline Yes $(n=82)$ & $132.2(16.3)$ & 0.498 & $147.6(13.3)$ & 0.051 \\
\hline No $(n=118)$ & $133.8(16.1)$ & & $150.0(13.2)$ & \\
\hline
\end{tabular}


Integration of Knowledge and Practice of Nurses' Primary Health Care Roles in Hospital

Table 5. Extent of nurses' PHC roles as perceived by patients in government and non-government hospitals

\begin{tabular}{|lccc|}
\hline Extent of PHC Roles & $\begin{array}{c}\text { Government } \\
\text { Mean (SD) }\end{array}$ & Non-Government & Pean (SD) \\
\hline Patients' perception & $(\mathrm{N}=100)$ & $(\mathrm{N}=100)$ & $<0.001$ \\
Clinician Role & $27.3(5.9)$ & $30.6(6.4)$ & $<0.001$ \\
Developmental Role & $26.8(6.0)$ & $30.6(6.4)$ & $<0.001$ \\
Facilitative Role & $25.4(5.3)$ & $28.4(7.1)$ & $<0.001$ \\
Supportive Role & $27.8(5.1)$ & $31.0(6.3)$ & $<0.001$ \\
Total & $107.3(19.0)$ & $120.5(24.3)$ & $<$ \\
\hline \hline
\end{tabular}

Table 6. Differences in nurses' PHC Roles regarding practice as perceived by the nurse and patient.

\begin{tabular}{|lccc|} 
& \multicolumn{2}{c}{ Nurse's PHC role practice } & P-value \\
& Mean & SD & \\
\hline Nurse & 133.2 & 16.1 & $<.001$ \\
Patient & 113.7 & 22.7 & \\
\hline \hline
\end{tabular}

\section{CONCLUSION}

Good nursing education program is very important for nurses to practice PHC roles efficiently and effectively in hospital. Good nursing programs may include sufficient physical conditions, experienced teaching staff, opportunities for practice and development of realistic plans that consider the availability of human and financial resources.

There is need for nurses to understand and deliver care congruent with patient's perception of quality nursing care. It is also concluded that with regular and facilitative supervision, it is expected that the nurses will have the guidance, encouragement, and resources they need to perform well.

\section{ACKNOWLEDGEMENTS}

I would like to thank my research advisors at NIPH Dr. Kayako HIRANO, Dr. Yashiharu FUKUDA, Dr. Yoko HATONO and the members of JOCS team. This study is a part of undertaking research for DPH program.

\section{REFERENCES}

1. Dixit H. The quest for health. 2nd ed. Kathmandu. Educational enterprises (P) Ltd; 1999.
2. Knopke HJ, Diekelmann NL, editors. A system approach to curriculum in primary health care: approaches to teach primary health care. St.Louis, CV. Mosby Co; 1981.

3. Van-den AB. Dispelling nurses' fear about primary health care. Inter Nurs Review. 1988; 34.

4. Singh I. Certificate nursing curriculum. HLMC. Kathmandu. 1987.

5. Aksayan S. Education of nurses for primary health care. World Health Forum. 1994; 15: 150-2.

6. Orem DE, Renpenning KM, Taylor SG. Self care theory in nursing: Selected papers of Dorothea Orem. New York: Springer. 2003.

7. Cha YM. Holistic nursing care rendered to medical-surgical patients. Baguio City: SLU. 1996; 124-5.

8. Statistical Package of Social Science. Version 11.5. Chicago: SPSS Inc. 2002.

9. Canadian Nurses Association. Primary health care- the time has come. Ottawa: Canadian Nurses Association. 2003.http://cnaaiic.ca/CNA/documents/pdf/publications/primaryhealthcare_ Sept_2003_e.pdf.

10. Gilson L, Sen PD, Mohammed S, Mujinja P.The potential of health sector on-governmental organizations: policy options. Health Policy Plan 1994; 9: 14-24.

11. Tavrow P, KimYM, Malianga L. Measuring the quality of supervisor provider interaction in health care facilities in Zimbabwe. Int J Qual Health Care. 2002; 14 Suppl 1: 57-66.

12. Mann S, Byrnes T. Bridging the gap. Community partnerships in nursing education: advancing primary health care in practice. Collegian 2000; 7(3): 14-20.

13. Clark J. The unique function of the nurse. Nurs Stand. 1998; 12(16): 39-42.

14. Perla L. Patient compliance and satisfaction with nursing care during delivery and recovery. J Nurs Quality. 2002; 16: 60-2. 